\title{
Thyroid cancer and renal transplantation: a meta-analysis
}

\section{Dheeraj Karamchandani ${ }^{1}$, Ramiro Arias-Amaya ${ }^{3}$, Nora Donaldson ${ }^{3}$, Jackie Gilbert ${ }^{3}$ and Klaus-Martin Schulte ${ }^{1,2}$}

\author{
${ }^{1}$ Department of Endocrine Surgery, King's College Hospital NHS Foundation Trust, King's College London, Denmark Hill, \\ London SE5 9RS, UK \\ ${ }^{2}$ Biostatistics Unit, King's College London Dental Institute, London, UK \\ ${ }^{3}$ Department of Endocrinology, King's College Hospital, London, UK \\ (Correspondence should be addressed to K-M Schulte; Email: klaus-martin.schulte@kch.nhs.uk)
}

\begin{abstract}
Kidney transplantation and the associated immune suppression are associated with a significantly increased risk of developing cancer during long-term follow-up. Thyroid cancer has been recognised as a potential post-transplant risk but has not yet been subject of a focused review. We therefore performed a meta-analysis on data of 50861 patients with a total follow-up of 198595 patient-years and identified a 6.9-fold higher standardised incidence ratio (95\% confidence interval 5.6-8.7, $P<0.001$ ) of thyroid cancer post renal transplantation as compared with a non-transplant group. All such cancers were of papillary type as far as histopathology was known. The mean time to discovery was 6.0 years post transplantation. This puts thyroid cancer into the group of high cancer risk following solid organ transplantation which already includes cervical cancer, non-melanoma skin cancer, oral and lip cancer and haematological malignancies. It is unclear what causes the increased cancer incidence. Inclusion of thyroid ultrasound in long-term post-transplant evaluation may help to ensure timely recognition of this condition.
\end{abstract}

Endocrine-Related Cancer (2010) 17 159-167

\section{Introduction}

Organ transplantation is currently considered the best option available in most types of end-stage organ failure. Success rates of organ transplantation have significantly improved over recent decades. This success mostly relates to improvements in immunosuppressive therapy and long-term care. However conversely, patients are now exposed to the longterm consequences of impaired immune function.

One meta-analysis of population-based studies indicates a significant increase in thyroid cancer in renal transplant patients among many other cancers (Grulich et al. 2007). These include cancers of the cervix, lip, skin and lymphomas (Grulich et al. 2007).

At present, it is not clear if addition of further data would corroborate the outcome of this former metaanalysis as far as thyroid cancer is concerned, which kind of thyroid cancer is observed, or at which time interval such transplant-related thyroid cancer appears.
In view of this, we focused on thyroid cancer in renal transplant recipients and carried out a meta-analysis with review of thyroid-specific information.

\section{Materials and methods}

In designing our meta-analysis, we reviewed published work available of conducting meta-analyses of observational studies (Stroup et al. 2000, Wright et al. 2007). Accordingly, we defined the below criteria for studies to be entered into the meta-analysis:

Inclusion criteria

1) All studies had to be published in English

2) All studies were cohort studies of organ transplant recipients

3) Studies matched transplant population to standardised population to calculate a standardised incidence ratio (SIR)

4) Studies stated incidence of thyroid cancer and SIR of thyroid cancer 
Exclusion criteria

1) Bone marrow transplantation studies were excluded

2) Some studies collected data on incident cancer through cancer registries in developed countries. Those studies that merely accepted thyroid or other cancer diagnoses without confirming that these were notified to a cancer registry were excluded

The author (D K) searched for articles reported up to January 2009 in PubMed, with the combination of search terms 'cancer', 'transplantation', 'thyroid', 'organ', 'transplant', 'renal' and 'immunosuppression'. The search was restricted to studies published in English. The search results were restricted to the presence of these words in the title or abstract of the articles.

A preliminary search of these terms yielded 13477 search items. The author (D K) went through all these items and identified 288 relevant publications based on the title of these of publications. Study of the abstracts of these 288 publications identified 120 publications which seemed to contain relevant data. These 120 publications were read in full-text and scrutinised for the presence of data allowing safe calculation of the SIR. This process revealed nine studies appropriate for analysis based on the criteria set out above. In addition to this, the references of the nine relevant articles were also scrutinised to identify any further articles not revealed by the above search. All the studies included in this publication were reviewed in full by all authors.

In addition, any further data required for conducting the analysis were obtained by contacting the relevant authors of the studies included to obtain any data not provided in the former publication.

The data were then extracted and analysed. We identified observed and expected numbers of cancer cases by selected cancer sites or grouping of sites. The authors (N D \& R A-A) carried out the statistical analysis. The SIRs of commonly known cancers and cancers well established to have increased risk in the organ transplant population were compared with that of thyroid cancer. In addition, features such as mean age of patients at transplantation, the mean time to development of cancer, the number of thyroid cancers and histology were tabulated, where available. We also attempted to obtain data on how these thyroid cancers were originally identified. We identified whether detection occurred in the setting of a structured screening programme or was an incidental discovery by contacting the authors of the studies. The majority of studies available for evaluating thyroid cancer in the transplant population is retrospective and predominantly review the cancer risk in the renal transplant population. All but one study were found to report on renal transplant patients. In order to reduce any form of bias, only data related to renal transplantation were reviewed in our analysis. The SIRs were specifically calculated and requested from authors for the relevant cancers used in our comparison.

The number of cancer cases observed and expected was tabulated by cancer site and in cases, where the expected cases were not presented, this was calculated by using the reported SIRs. The overall SIRs for the studies were calculated by author (R A-A and N D) by weighting the studies based on their sample size.

Table 1 Distribution of organ transplants in included studies

\begin{tabular}{|c|c|c|c|c|c|c|c|}
\hline Study authors & $\begin{array}{l}\text { Renal } \\
\text { transplants } \\
(n)\end{array}$ & $\begin{array}{l}\text { Liver } \\
\text { transplants } \\
(n)\end{array}$ & $\begin{array}{l}\text { Heart } \\
\text { transplants } \\
(n)\end{array}$ & $\begin{array}{l}\text { Lung } \\
\text { transplants } \\
(n)\end{array}$ & $\begin{array}{l}\text { Pancreas } \\
\text { transplants } \\
(n)\end{array}$ & $\begin{array}{l}\text { Combination } \\
\text { transplantation } \\
(n)\end{array}$ & $\begin{array}{l}\text { Recipients } \\
\text { of renal } \\
\text { transplants } \\
(n)\end{array}$ \\
\hline Hoshida et al. 1997 & 1744 & 0 & 0 & 0 & 0 & 0 & 1744 \\
\hline Adami et al. 2003 & 5004 & 394 & 236 & 117 & 26 & 154 & 5931 \\
\hline Birkeland et al. 2000 & 1821 & 0 & 0 & 0 & 0 & 0 & 1821 \\
\hline Kyllonen et al. 2000 & 3440 & 0 & 0 & 0 & 0 & 0 & 2890 \\
\hline Pond et al. 2005 & 10989 & 0 & 0 & 0 & 0 & 0 & 10989 \\
\hline Vajdic et al. 2006 & 10180 & 0 & 0 & 0 & 0 & 0 & 10180 \\
\hline Makitie et al. 2008 & 3440 & 0 & 0 & 0 & 0 & 0 & 2890 \\
\hline Végso et al. 2007 & 2852 & 0 & 0 & 0 & 0 & 0 & 2535 \\
\hline Villeneuve et al. 2007 & 11391 & 0 & 0 & 0 & 0 & 0 & 11391 \\
\hline Total $(n)$ & 50861 & 394 & 236 & 117 & 26 & 154 & 51788 \\
\hline Percentage of total & 98.2 & 0.8 & 0.5 & 0.2 & 0.1 & 0.3 & 100.1 \\
\hline
\end{tabular}

The number of renal transplants indicates the number of organ transplant procedures performed. The column 'recipients of renal transplants' indicates the number of patients receiving these transplants. Data relating to non-renal transplant were excluded from meta-analysis in order to avoid a bias. 


\begin{tabular}{|c|c|c|c|c|c|}
\hline & Study title & Type of study & Multicentre & $\begin{array}{l}\text { Type of } \\
\text { transplant }\end{array}$ & $\begin{array}{l}\text { Number of } \\
\text { patients in } \\
\text { study }(n)\end{array}$ \\
\hline 1 & $\begin{array}{l}\text { Cancer risk after renal } \\
\text { transplantation in Japan } \\
\text { (Hoshida et al. 1997) }\end{array}$ & Retrospective & Yes & Renal & 1744 \\
\hline 2 & $\begin{array}{l}\text { Cancer risk following organ } \\
\text { transplantation: a nationwide } \\
\text { cohort study in Sweden } \\
\text { (Adami et al. 2003) }\end{array}$ & Retrospective & Yes & Multiorgan & 5931 \\
\hline 3 & $\begin{array}{l}\text { Cancer risk in patients on dialysis } \\
\text { and after renal transplantation } \\
\text { (Birkeland et al. 2000) }\end{array}$ & Retrospective & Yes & Renal & 1821 \\
\hline 4 & $\begin{array}{l}\text { Cancer incidence in a kidney- } \\
\text { transplanted population } \\
\text { (Kyllonen et al. 2000) }\end{array}$ & Retrospective & Yes & Renal & 2890 \\
\hline 5 & $\begin{array}{l}\text { Thyroid cancer in the renal } \\
\text { transplant population: } \\
\text { epidemiological study } \\
\text { (Pond et al. 2005) }\end{array}$ & Retrospective & Yes & Renal & 10989 \\
\hline 6 & $\begin{array}{l}\text { Cancer incidence before and } \\
\text { after kidney transplantation } \\
\text { (Vajdic et al. 2006) }\end{array}$ & Retrospective & Yes & Renal & 10180 \\
\hline 7 & $\begin{array}{l}\text { Head and neck cancer in renal } \\
\text { transplant patents in Finland } \\
\text { (Makitie et al. 2008) }\end{array}$ & Retrospective & Yes & Renal & 2890 \\
\hline 8 & $\begin{array}{l}\text { Malignancies after renal } \\
\text { transplantation during } \\
33 \text { years at a single centre. } \\
\text { (Végso et al. 2007) }\end{array}$ & Retrospective & No & Renal & 2535 \\
\hline 9 & $\begin{array}{l}\text { Cancer incidence among } \\
\text { Canadian kidney } \\
\text { transplant recipients } \\
\text { (Villeneuve et al. 2007) }\end{array}$ & Retrospective & Yes & Renal & 11391 \\
\hline
\end{tabular}

\section{Statistical analysis}

In our meta-analysis, we obtained an estimate from each study of the unadjusted relative risk (RR) with 95\% confidence intervals (CIs). We used a random effect model and calculated pooled effects (95\% CIs) for RR using the inverse variance method. We performed the Breslow-Day test for homogeneity of RRs, Cochran-Mantel-Haenszel test for the null hypothesis of no effect $(R R=1)$, and the Mantel-Haenszel common $\mathrm{RR}$ estimate and depicted results using a forest plot. We assessed publication bias by using a funnel plot and Begg's test to find out whether there was a bias towards publication of studies with positive results among the smaller studies. We also examined the influence of individual studies, in which the meta-analysis estimates are derived omitting one study at a time to see the extent to which inferences depend on a particular study or group of studies. The statistical package STATA v9.1 (www.stata.com) was used.

\section{Results}

Our analysis included nine studies comprising a total of 50371 pure renal transplants $(98.2 \%)$ and 927 mixed and other solid organ transplants (1.8\%; Table 1). These studies were based in a number of countries, which included Australia and New Zealand, Canada, Denmark, Finland, Hungary and Sweden. We considered the sample size of the mixed and nonrenal transplant group as too small for meta-analysis. As a consequence, only patients who underwent renal transplantation were included here.

Table 2 shows a summary of the studies included in our analysis with details of the studies. As can be noted, all the studies were retrospective and the largest study had over 11000 patients.

The overall mean age at transplantation was 44.4 years (range: $40.3-53.1$ years) with a mean follow-up time of 8.2 years (Table 3). In total, all the studies 


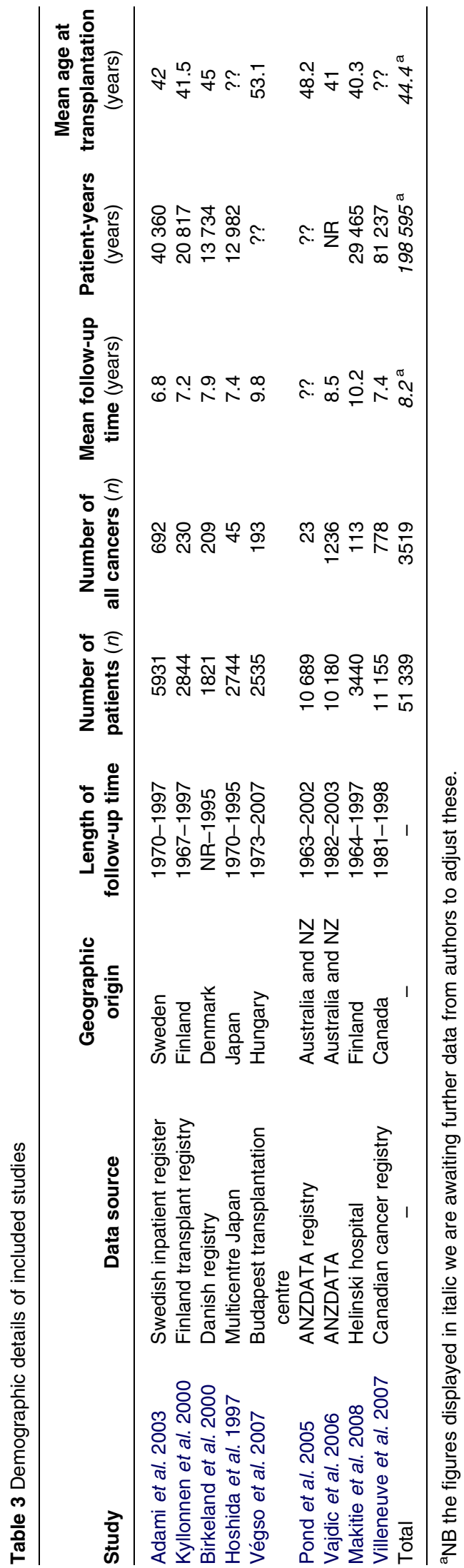

accumulated a surveillance of 198595 patient-years. A total number of 3519 cancers and haematological malignancies were observed (Table 3).

Meta-analysis for the SIR for thyroid cancer showed it to be significantly elevated at 6.94 (95\% CI 5.55-8.69; $P<0.001)$. Figure 1 shows the forest plot for individual and overall RR measures. The pooled estimate of RRs using the random effect model (RR) was 6.94 (95\% CI 5.55-8.69; $P<0.001)$. Heterogeneity test was not significant $(Q=12.47$, $P=0.131)$. There was no evidence of publication bias using Begg's test ( $P=0.118$; Fig. 2).

A sensitivity analysis (Table 4) indicates that the omission of any of the studies led to changes in estimates between $6.13(4.92-7.64)$ and 8.01 (6.83-9.40). The changes were not significant.

The more common epithelial cancers such as breast, prostate, colorectal and ovarian were not significantly increased in the transplant population (Table 5). In addition, cancers related to viral infection such as nonmelanoma skin, cervix uteri and lip cancers were found at increased rates in the transplant population (Table 5). Kidney and bladder cancers were also found to be increased in the transplant population (Table 5).

None of the studies had routine neck US scanning as part of their screening post renal transplantation. In total, there were 115 thyroid cancers and almost all were noted to be papillary carcinomas (Table 6). The overall mean time to thyroid cancer development with the day of transplantation defined as day 0 was 72.0 months as compared to the 92.7 months for all other cancers.

\section{Discussion}

Our data show that the risk of thyroid cancer is significantly increased following allogenic kidney transplantation (SIR $6.94 \quad 95 \%$ CI $5.55-8.69$ $P<0.001)$. The majority of cancer appears about 6 years following transplant. With the exception of those cancers with unspecific histology, they all are of papillary type.

Conversely, malignancies commonly encountered in the general population, such as carcinoma of the breast, prostate, lung and colon, are not seen more frequently in transplant recipients.

It is uncertain as to whether the increased risk of thyroid cancer post transplantation is related to chronic immune suppression alone or eventually also related to pre-existing cancer risk factors. End-stage kidney 


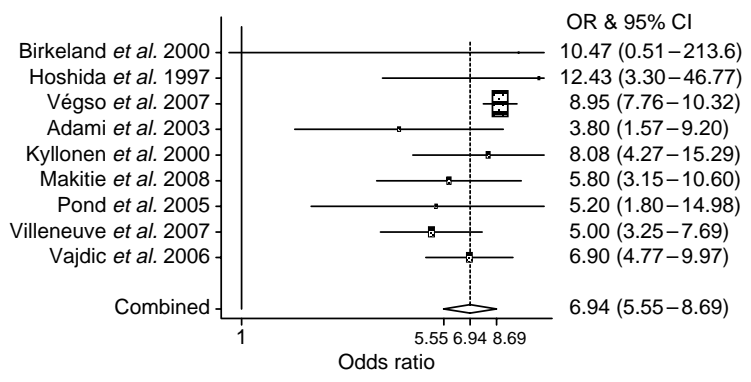

Figure 1 The Forest plot depicts the scattering of the odds ratio (OR) with $95 \%$ confidence intervals $(\mathrm{Cl})$ for the studies entering meta-analysis. The squares indicate sample size as inverse variance weights. The rhombus indicates the OR of the combined studies with $95 \% \mathrm{Cl}$.

disease (ESKD) or dialysis is associated with an increased risk of cancer in general as demonstrated in a study of long-term cancer incidence of 831804 patients on dialysis (Maisonneuve et al. 1999). Importantly, the overall cancer risk associated with ESKD was lower than the risk post transplantation. Studies that fail to record the increased cancer risk in patients with ESKD still show an increased risk for thyroid cancer in dialysis patients $(\mathrm{RR}-2.0$; Kantor et al. 1987). As far as thyroid cancer is concerned, a study by Brunner et al. (1995) which mapped cancer incidences using European Dialysis and Transplant Association-European Renal Association cancer registry found an increased incidence of thyroid cancer both in transplanted patients as well as in patients with chronic renal failure treated by maintenance haemodialysis. The vast majority of cancer occurrence in post-transplant recipients is that of de novo cancer

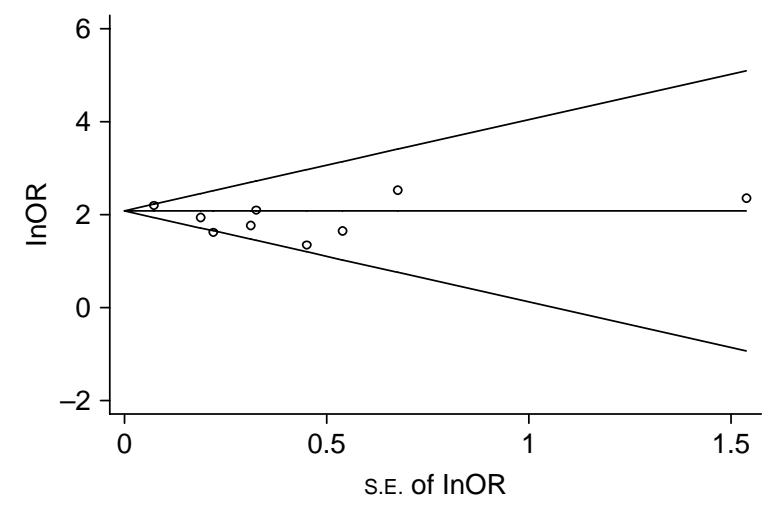

Figure 2 The funnel plot shows the scatter plot of the natural logarithm of the odds ratio (InOR) of SIR of thyroid cancer on the vertical axis as an expression of the effects of transplantation on disease-specific mortality plotted against the standard error of the natural logarithm of the odds ratio of SIR (S.E.M. of InOR) of thyroid cancer on the horizontal axis as an expression of the study size. Begg's test has not identified a significant funnel plot asymmetry $(P=\mathrm{NS})$. rather than the result of an ascertainment bias (Vajdic et al. 2006). In addition, we noted that neck US scanning was not part of routine screening in any of the studies, thus it is likely that all thyroid cancers detected were incidental findings. The lack of excess risk of prostate and breast cancers (commonly diagnosed by opportunistic screening) also argues against this bias playing an important role. However, these inferences need to be treated with the caveat that specifically papillary thyroid cancer can have a very long latency. Our data show that the average time of discovery of the thyroid cancer is 6 years following transplant. It is impossible to know how many of these cancers would have been initiated in the pre-transplant episode. The most important question in this matter is whether the rate of de novo initiation or growth of cancers or both factors are altered by the post-transplantation state. Indeed, it is not unlikely that post-transplant immunosuppression could have modified the clinical course of latent disease which thereby became clinically detectable and relevant. We can only speculate as to the drivers behind thyroid carcinogenesis in the setting of chronic immune depression. There is considerable evidence that viral infection may contribute to thyroid carcinogenesis, including enteroviruses, Epstein-Barr virus (Shimakage et al. 2003), and human papilloma virus B19 (Wang et al. 2008), and human hepatitis C virus (Antonelli et al. 2009). Immune surveillance by dendritic cells may be among the mechanism of thyroid cancer control (Schott 2006). The pattern of solid organ cancers found to be increased following renal transplantation seems to be associated with a viral oncogenic pathway of induction, such as cervical cancer, non-melanoma skin cancer and lip cancer. Thyroid and renal cancers seem to be an exception to this pattern as noted from our analysis.

It would be of interest to determine whether an increased risk of cancer (specifically thyroid cancer) is present in other immunodeficient populations.

Table 4 Sensitivity analysis

\begin{tabular}{lccr}
\hline Study omitted & RR & 95\% Confidence Intervals \\
\hline Birkeland et al. 2000 & 6.87 & 5.42 & 8.70 \\
Hoshida et al. 1997 & 6.78 & 5.35 & 8.59 \\
Végso et al. 2007 & 6.13 & 4.92 & 7.64 \\
Adami et al. 2003 & 7.31 & 5.95 & 8.99 \\
Kyllonen et al. 2000 & 6.72 & 5.20 & 8.70 \\
Makitie et al. 2008 & 7.05 & 5.53 & 8.99 \\
Pond et al. 2005 & 6.99 & 5.52 & 8.86 \\
Villeneuve et al. 2007 & 8.01 & 6.83 & 9.40 \\
Vajdic et al. 2006 & 6.80 & 5.14 & 90.00 \\
Combined & 6.94 & 5.55 & 8.69 \\
\hline
\end{tabular}




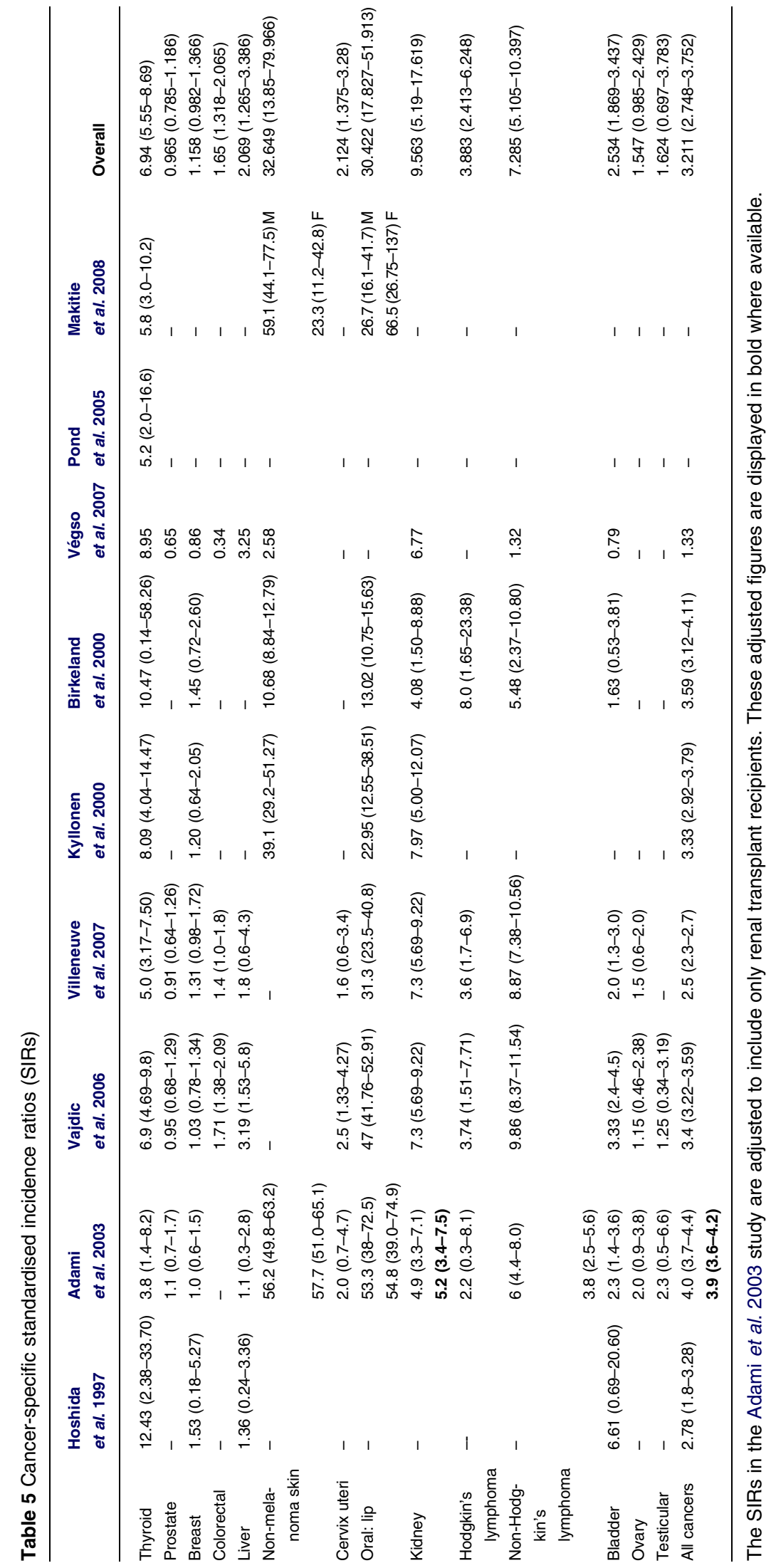




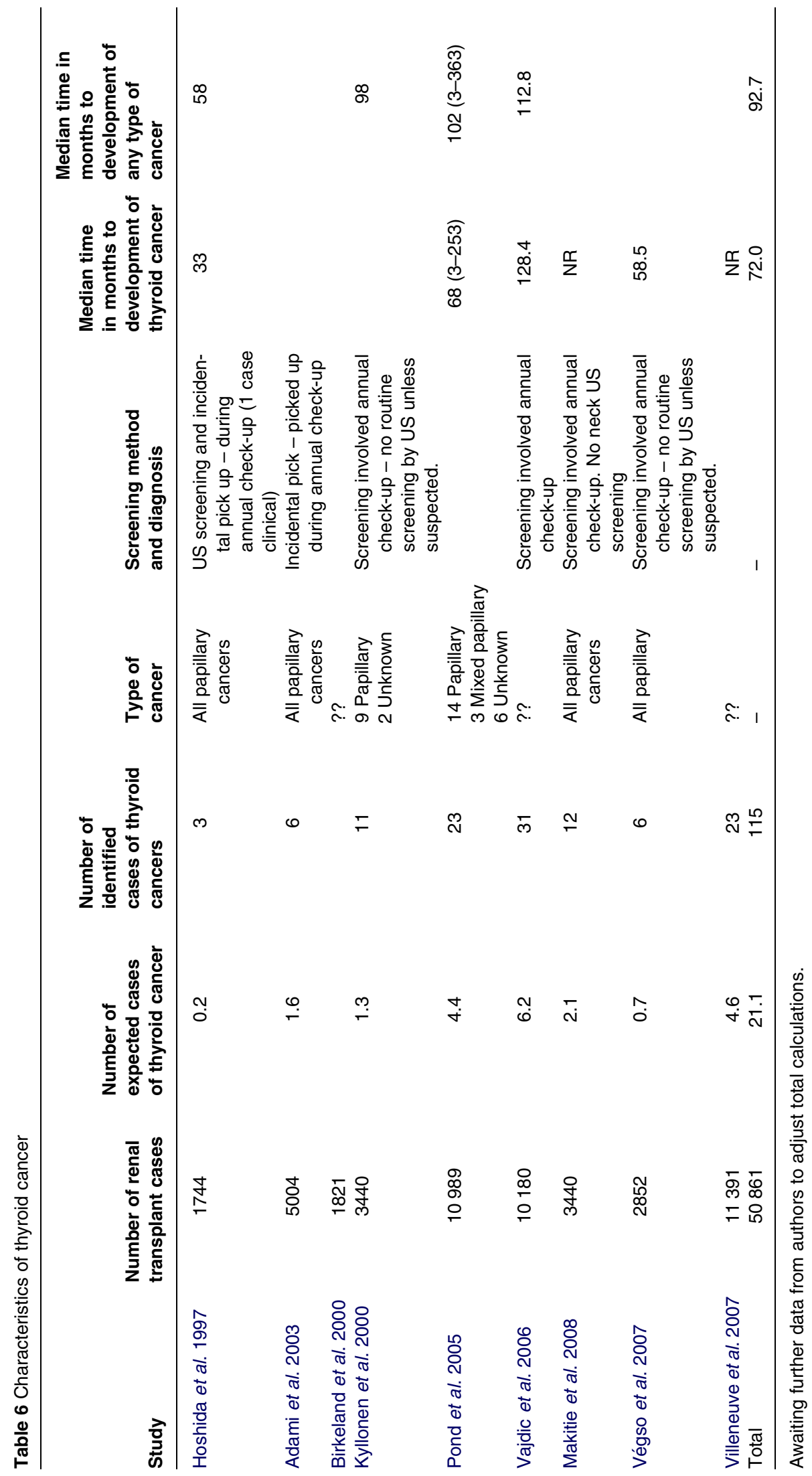


Grulich et al. (2007) have recently conducted a metaanalysis which compared the incidence of malignancy in people with HIV/AIDS and transplant recipients. They evaluated seven studies of people with HIV/ AIDS $(n=44172)$ and five studies of transplant recipients $(n=31$ 977). Interestingly, a similar pattern of increased risk of malignancy was identified in both populations (20 out of the 28 malignancies investigated). A large proportion of these 20 malignancies were associated with a known or suspected viral aetiology. The common epithelial cancers such as cancers of the colon, breast, rectum, ovary and prostate were not found to be increased in either population. The trends noted in this study were very similar to the pattern noted in our analysis. However, whereas there was an increased risk of thyroid cancer in the transplant population (5.91 95\% CI 4.41-7.90), there was no increased risk of thyroid cancer in the HIV/AIDS population. This suggests that different immune mechanisms may be responsible for the development of thyroid cancer in immunosuppressed transplant patients. However, the differential immune modulation that results from treating these two patient groups provides a significant confounding factor. The majority of patients in the HIV/AIDS group was likely to be treated with combination anti-retroviral agents. It is possible that anti-retroviral agents interact directly with the mechanisms involved in the development of thyroid cancer. By evaluating the immune profiles of the HIV/AIDS population and comparing it to the transplant population, we may be able to determine what factors account for this observed difference in thyroid cancer risk.

The debate on the presumed cause of thyroid cancer should not overshadow the important conclusion which needs to be drawn from these results. Our analysis shows that all thyroid cancers occurring in the post-transplant setting are of papillary type, as far as specific histopathology information was available. Papillary thyroid cancer has an excellent prognosis with timely detection and appropriate treatment (Mazzaferri 2009). We therefore feel that ultrasound screening for thyroid lesions prior to transplantation and yearly thereafter during routine post-transplant surveillance should help to control a recognised risk factor in the long-term course.

\section{Conclusion}

Our meta-analysis has clearly demonstrated that the standardised incidence rate of thyroid cancer is elevated in renal transplant recipients. While the origin of this phenomenon is not clear, it supports the use of thyroid ultrasound in the pre- and post-transplant setting in order to ensure timely detection of a curable disease.

\section{Declaration of interest}

The authors declare that there is no conflict of interest that could be perceived as prejudicing the impartiality of the research reported.

\section{Funding}

This research did not receive any specific grant from any funding agency in the public, commercial or not-for-profit sector.

\section{Acknowledgements}

D K, R A-A, N D, J G and K-M S are all King's Heath Partners. We would like to thank the authors of the studies that were used in our meta-analysis. We would like to thank the following authors for the additional data that they provided us: Dr G Végso, Dr J Adami, Dr C Vajdic and Dr P J Villeneuve.

\section{References}

Adami J, Gäbel H, Lindelöf B, Ekström K, Rydh B, Glimelius B, Ekbom A, Adami H-O \& Granath F 2003 Cancer risk following organ transplantation: a nationwide cohort study in Sweden. British Journal of Cancer $\mathbf{8 9}$ 1221-1227.

Antonelli A, Ferri C, Ferrari SM, Colaci M, Sansonno D \& Fallahi P 2009 Endocrine manifestations of hepatitis C virus infection. Nature Clinical Practice. Endocrinology \& Metabolism 5 26-34.

Birkeland SA, Lokkegaard H \& Storm HH 2000 Cancer risk in patients on dialysis and after renal transplantation. Lancet 355 1886-1887.

Brunner FP, Landais P \& Selwood NH 1995 Malignancies after renal transplantation: the EDTA-ERA registry experience. European Dialysis and Transplantation Association-European Renal Association. Nephrology, Dialysis, Transplantation 10 S74-S80.

Grulich AE, van Leeuwen MT, Falster MO \& Vajdic CM 2007 Incidence of cancers in people with HIV/AIDS compared with immunosuppressed transplant recipients: a meta-analysis. Lancet 370 59-67.

Hoshida Y, Tsukuma H, Yasunaga Y, Xu N, Fujita MQ, Satoh T, Ichikawa Y, Kurihara K, Imanishi M, Matsuno T et al. 1997 Cancer risk after renal transplantation in Japan. International Journal of Cancer 71 517-520.

Kantor AF, Hoover RN, Kinlen LJ, McMullan MR \& Fraumenti JF Jr 1987 Cancer in patients receiving long-term dialysis treatment. American Journal of Epidemiology 126 370-376.

Kyllonen L, Salmela K \& Pukkala E 2000 Cancer incidence in a kidney-transplanted population. Transplant International 13 S394-S398. 
Maisonneuve P, Agodoa L, Gellert R, Stewart JH, Buccianti G, Lowenfels AB, Wolfe RA, Jones E, Disney AP, Briggs $\mathrm{D}$ et al. 1999 Cancer in patients on dialysis for end-stage renal disease: an international collaborative study. Lancet 354 93-99.

Makitie AA, Lundberg M, Salmela K, Kyllönen L \& Pukkala E 2008 Head and neck cancer in renal transplant patients in Finland. Acta Otolaryngologica 128 1255-1258.

Mazzaferri EL 2009 What is the optimal initial treatment of low-risk papillary thyroid cancer (and why is it controversial)? Oncology 23 579-588.

Pond F, Serpell JW \& Webster A 2005 Thyroid cancer in the renal transplant population: epidemiological study. Australian and New Zealand Journal of Surgery 75 106-109.

Schott M 2006 Immunesurveillance by dendritic cells: potential implication for immunotherapy of endocrine cancers. Endocrine-Related Cancer 13 779-795.

Shimakage M, Kawahara K, Sasagawa T, Inoue H, Yutsudo M, Yoshida A \& Yanoma S 2003 Expression of Epstein-Barr virus in thyroid carcinoma correlates with tumor progression. Human Pathology 34 1170-1177.

Stroup DF, Berlin JA, Morton SC, Olkin I, Williamson GD, Rennie D, Moher D, Becker BJ, Sipe TA \& Thacker SB 2000 Meta-analysis of observational studies in epidemiology: a proposal for reporting. Meta-analysis of Observational Studies in Epidemiology (MOOSE) Group. Journal of the American Medical Association 283 2008-2012.

Vajdic CM, McDonald SP, McCredie MRE, van Leeuwen MT, Stewart JH, Law M, Chapman JR, Webster AC, Kaldor JM \& Grulich AE 2006 Cancer incidence before and after kidney transplantation. Journal of the American Medical Association 296 2823-2831.

Végso G, Tóth M, Hídvégi M, Toronyi E, Langer RM, Dinya E, Tóth A, Perner F \& Járay J 2007 Malignancies after renal transplantation during 33 years at a single center. Pathology Oncology Research 13 63-69.

Villeneuve PJ, Schaubel DE, Fenton SS, Shepherd FA, Jiang Y \& Mao Y 2007 Cancer incidence among Canadian kidney transplant recipients. American Journal of Transplantation 7 941-948.

Wang JH, Zhang WP, Liu HX, Wang D, Li YF, Wang WQ, Wang L, He FR, Wang Z, Yan QG et al. 2008 Detection of human parvovirus B19 in papillary thyroid carcinoma. British Journal of Cancer 98 611-618.

Wright RW, Brand RA, Dunn W \& Spindler KP 2007 How to write a systematic review. Clinical Orthopaedics and Related Research 455 23-29. 